C2020, Elsevier. Licensed under the Creative Commons Attribution-NonCommercialNoDerivatives 4.0 International http://creativecommons.org/about/downloads

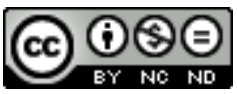

Full published version can be found here: https://doi.org/10.1016/j.respol.2020.103958 


\title{
Analogical Reasoning, Cognition, and the Response to Technological Change: Lessons from Mobile Communication
}

\begin{abstract}
We examine how analogical reasoning affects cognition and investment decisions in the face of technological change. Our research design is an in-depth, longitudinal case study of Nokia and its response to mobile Internet between the late 1990s and the mid-2010s. We show that Nokia diligently analyzed the competitive dynamics of other industries, such as the personal computer industry, that had already been affected by the same technological discontinuities and used such lessons from these industries to anticipate future competition outcomes in the mobile phone business. We also show that analogical reasoning helped Nokia's managers change the beliefs developed through their prior experiences. However, Nokia's managers became overconfident in their new beliefs, and this overconfidence constrained their cognitive processes of attention and interpretation, thereby increasing organizational inertia. This constraint was particularly evident in the new belief that the software operating system was the essential source of product differentiation. This belief directed key investment decisions for over a decade and contributed to the eventual decline of Nokia by leading the company to embrace Microsoft's Windows Phone rather than Google's Android.
\end{abstract}

Keywords: analogy; strategy making; cognition; overconfidence; inertia; technological change 


\section{Introduction}

Cognitive representations are a critical determinant of managerial choices and actions (Barr, 1998; Fiol, 1990; Nightingale, 1998). The long-term performance of firms in the face of technological discontinuities, in particular, is often the result of managers' representations of such discontinuities (Nadkarni and Barr, 2008; Walsh, 1995).

The extant research on cognition primarily focuses on the relationship between managerial beliefs and strategic outcomes (Eggers and Kaplan, 2013; Kaplan, 2008b; Tripsas and Gavetti, 2000). This research shows that senior managers often struggle to evolve their mental frames in rapidly changing environments and that this struggle leads to organizational inertia (Garud and Rappa, 1994; Kiesler and Sproull, 1982; Thrane et al., 2010).

While most scholars have focused on the impact of managerial beliefs on strategic outcomes, other scholars have explored the cognitive dynamics that occur in organizations. This work has shown that strategic beliefs are not static and that decision-making processes can deeply affect the evolution of managers' mental models (Garud et al., 2010; Laamanen and Wallin, 2009; Szulanski et al., 2004). In particular, some scholars have focused on the role of analogical reasoning in informing managerial beliefs (Gary et al., 2012; Gavetti et al., 2005). In this paper, we expand this latter work by examining the relationship between analogical reasoning and managerial cognition in the midst of technological discontinuities and the effects of this relationship on investment decisions.

Our research design is an in-depth, longitudinal case study of Nokia and the mobile phone industry between the late 1990s and mid-2010s, when the Finnish company had to cope with the advent of new $3 \mathrm{G}$ wireless communication technologies (i.e., the mobile Internet) and the convergence of digital technologies (e.g., games, imaging, music, and software applications) into 
mobile communication. To sustain its leadership, Nokia relied on formal, systematic approaches to strategic decision-making and extensively used analogical reasoning. Top executives diligently analyzed the competitive dynamics of other industries—-such as the personal computer (PC) industry — that had already been affected by the same technological discontinuities and used the lessons that they gained from these industries to anticipate future competition outcomes in the mobile phone business.

Our findings show that analogical reasoning strongly contributed to changing the beliefs Nokia's managers developed through the prior experiences of their company and industry. This was the case, in particular, for the new belief that the company could not differentiate its $3 \mathrm{G}$ handsets without differentiating the software operating system. Remarkably, under the previous $2 \mathrm{G}$ technological paradigm, mobile handsets had not run any operating systems, and Nokia had historically based its success on other sources of differentiation, such as product design, brand recognition, hardware performance, array of models, and time to market.

The new belief about the essential role of the software operating system originated from the analogy of the rise of Microsoft and the decline of hardware manufacturers in the PC industry. This managerial belief directed key investment decisions for more than a decade: it led Nokia first to develop Symbian in the early 2000s and then to embrace Microsoft's Windows Phone (rather than Google's Android) in the early 2010s.

Overall, our work shows that although analogical reasoning helps managers to evolve their beliefs, the new beliefs themselves that analogical reasoning informs might become firmly held and constrain search processes in a turbulent environment. Managers might become overconfident in their new beliefs, and overconfidence (i.e., excessive certainty about one's assumptions) might increase organizational inertia rather than adaptation. 
The contribution of this paper is twofold. First, it expands our understanding of the cognitive dynamics behind the origin and evolution of managerial beliefs (Kaplan and Tripsas, 2008; Kaplan, 2008b). Second, this paper addresses the debate regarding the role of analogical reasoning and, more generally, strategy making in technology management (Farmer and Lafond, 2016; Gavetti and Menon, 2016; Hekkert et al., 2007).

\section{Analogical reasoning, cognition, and technological change}

\subsection{Managerial cognition and competition outcomes}

Cognition has long been a mainstream research field in management, as it emphasizes the role of managerial beliefs (i.e., mental models and strategic assumptions) in directing search processes in a changing environment, the evolution of organizational resources, and ultimately, competition outcomes (Laamanen et al., 2018; Nadkarni and Narayanan, 2007; Walsh 1995). The pioneering work of Kiesler and Sproull (1982) characterized managerial cognition as the process of noticing stimuli from the external environment, interpreting them, and integrating their meaning with other relevant information to make strategic decisions. Subsequent studies focused on two cognitive processes that are relevant to strategic decision-making, namely, attention and interpretation.

Regarding attention, Ocasio (1997, p. 202) argued that "the ability of the firm to adapt successfully to a changing environment is conditional on whether the firm's procedural and communication channels focus the attention of the organizational decision makers on an appropriate set of issues and answers". Empirical research has shown that managerial attention can explain firm choices and actions, such as the speed of the response to industry changes 
(Nadkarni and Barr, 2008), the timing of entry into a new product market (Eggers and Kaplan, 2009), the development of explorative and exploitative capabilities (Koryak et al., 2018), and the detection of weak signals that lead to a crisis (Rerup, 2009).

Concerning the cognitive process of interpretation, Daft and Weick (1984), Jackson and Dutton (1988), and Porac et al. (1995) explored how managers make sense of the abundant and unstructured information that they receive from a changing environment. Kaplan (2008b), Thomas et al. (1993), and Tripsas and Gavetti (2000) connected managerial interpretation to the strategic actions of organizations, as empirically observed, in relation to environmental discontinuities such as new technologies and customer needs.

The mainstream research on cognition has traditionally focused on the content issues of strategic beliefs (i.e., what managers believe) and their impact on competition outcomes. For instance, in the transition from analog to digital imaging, a firmly held managerial belief in a razor/blade business model significantly delayed Polaroid's commercialization of a stand-alone digital camera and ultimately jeopardized the capability of the company to adapt to its changing industry (Tripsas and Gavetti, 2000). Similar effects have been found in the shift from print to online newspapers (Gilbert, 2006), in pharmaceutical firms' responses to the emergence of biotechnology (Kaplan et al., 2003), and in communication technology firms' responses to fiber optics (Kaplan, 2008b).

These studies all generally emphasize that mental frames are a static representation of the business environment resulting from the prior history of managers and their companies (Kaplan and Tripsas, 2008). Specifically, according to Kaplan (2008b, p. 738), managerial beliefs depend on "previous experiences - including individual career histories, project experience, functional membership, position in the hierarchy — and contexts — including the firm, the industry and the 
prevailing technological paradigm". As they work together, over time, senior managers create a shared understanding of their external environment, i.e., a "dominant logic" that ultimately drives collective decisions and actions (Prahalad and Bettis, 1986). For instance, in the case of Polaroid, the belief of managers in the razor/blade business model was because of their previous experiences with the technology of analog imaging (Tripsas and Gavetti, 2000).

In changing industries, the difficulty of managers to adapt their static and history-based beliefs often constrains the scope of their search processes, which leads to organizational inertia and poor performance (Nadkarni and Barr, 2008). A crucial challenge is thus the ability to assess the accuracy of the beliefs inherited from previous experiences by distinguishing the beliefs that still correctly represent the evolving competitive landscape from the beliefs that instead represent "blind spots" (Kaplan, 2011; Walsh, 1995).

\subsection{Analogy and cognitive dynamics}

While most scholars have emphasized the content issues of managerial beliefs and the relationship between such content issues and strategic outcomes, as described above, other scholars have focused on the cognitive dynamics occurring in organizations. Instead of a static representation of cognition in which managers are depicted as constrained by rigid mental models, these scholars have portrayed cognition as a dynamic process that is influenced by and, in turn, influences the activities and patterns of strategic decision-making (Kaplan, 2008b; Laamanen and Wallin, 2009; Szulanski et al., 2004).

In particular, some scholars have emphasized the relevance of analogical reasoning in shaping the evolution of mental models in a novel situation (Gavetti et al., 2005; Gilboa and Schmeidler, 2001). Analogical reasoning occurs when the solution to a current problem is found 
through a perceived similarity between this current problem and another problem encountered in the past. Specifically, analogical reasoning involves using a familiar, prior situation (which is called the "source analog" or the "source problem") to make inferences and inform assumptions about a new situation (the so-called "target problem"). The transfer of insights from the source problem to the target problem might take the form of a suggested solution or a warning of a threat (Gary et al., 2012).

The application of analogies from a past problem to a novel situation can reduce complexity and uncertainty and enable managers to adapt their beliefs to a dynamic environment. However, several factors affect the benefits that decision makers can concretely achieve through analogical reasoning (Gavetti and Menon, 2016). First, the effectiveness of analogies depends on how managers identify the main features and characteristics of the target problem. Second, it depends on how managers search their library experiences in their memory to retrieve a prior situation (source problems) that has similar features to the target problem. Third, the effectiveness of analogies depends on the extent to which the solution inferred from the source problem gets adapted to reflect the peculiarities of the target problem.

In this regard, Gentner (1983) made a clear distinction between analogies premised on superficial features (i.e., features that characterize the source and target problems but that are not part of what makes a particular solution work) and analogies premised on relevant features or "structural relations". Structural relations are the underlying principles for why a given solution works well — or poorly_ in the source and the target problems: they are the higher order relationships governing the way something works, such as causal or functional relations. The key issue of analogical reasoning is to identify source problems that share exactly the same structural 
relations of the target problem (Gavetti et al., 2005). Without such structural alignment, managers are unlikely to find valuable solutions to external changes and novel situations.

\subsection{Analogy, cognition, and technological change}

Despite the growing interest of scholars, our knowledge regarding the relationship between analogical reasoning and cognition in the face of major technological discontinuities is relatively limited. In particular, a relevant issue that has remained unexplored is the impact of beliefs that stem from analogical reasoning on investment decisions regarding new technologies, products, and markets.

Previous work concerning strategy making and cognitive dynamics generally claims that managers tend to be overconfident in their emerging assumptions about the future and optimistic about the success of investments in new products and markets based on these assumptions, while this overconfidence often leads to poor organizational performance (Camerer and Lovallo, 1999; Simon and Houghton, 2003). Overconfidence implies that an individual's certainty that her or his assumptions are correct exceeds the accuracy of these assumptions; overconfidence is more likely to arise when managers make assumptions regarding less repetitive decisions (e.g., new product introductions or pioneering of new markets), face difficult tasks, and, more generally, when the environment is complex and uncertain (Kahneman and Lovallo, 1993; Klayman et al., 1999). However, thus far, no studies specifically addressed the case of business managers using analogical reasoning to cope with technological change or explored the (over)confidence of these managers in their emerging assumptions regarding new technologies, products and markets.

This lack of empirical research reveals a major gap in the extant literature and a major opportunity to expand our knowledge of analogical reasoning, cognitive dynamics, and 
competition outcomes. In this paper, we seek to seize this opportunity. We extend current theory and create new insights by exploring how analogical reasoning affects cognition and investment decisions in the face of technological discontinuities.

Given the critical influence of top executives on strategic investments and according to the previous work of mainstream scholars in the field of cognition, we focus on the beliefs of the senior management team (Barr et al., 1992; Nadkarni and Barr, 2008; Tripsas and Gavetti, 2000). Our central contribution concerns cognitive dynamics in corporate organizations, specifically the origin and evolution of managerial beliefs (Kaplan and Tripsas, 2008). We find that by expanding the analytical efforts of managers beyond the scope of their firms and industries, analogical reasoning can enrich their cognitive maps. Managers are likely to develop new beliefs that represent strong discontinuities from their idiosyncratic experiences. However, we also found that managers might become overconfident in the new beliefs that originate from analogical reasoning and that these beliefs can increase inertia rather than adaptation. We therefore add to our understanding of the advantages and limitations of technological forecasting and anticipatory approaches to innovation management (Hoisl et al., 2015; Nightingale, 2004).

\section{Data and methods}

Given the gap in the literature and the open-ended nature of our question, we adopted the case study methodology (Eisenhardt, 1989; Miles and Huberman, 1994). We used a single-case and longitudinal research design because it allows one to richly describe the existence of a phenomenon and the conditions under which this phenomenon might occur (Eisenhardt and Graebner, 2007). This research follows in the tradition of in-depth case studies to investigate 
managerial beliefs and their role in strategic responses to environmental change (Tripsas and Gavetti, 2000).

\subsection{Case selection}

The research setting is a major multinational company in a highly dynamic industry. Specifically, we studied the co-evolution of analogical reasoning, managerial beliefs and investment decisions at Nokia after the advent of the $3 \mathrm{G}$ wireless communication standard (i.e., the mobile Internet) and the convergence of digital functions (e.g., games, imaging, music, radio and television broadcasting) into mobile communication beginning in the late 1990s. Faced with these technological discontinuities, Nokia engaged in extensive analytical efforts and analogical reasoning to support its long-term leadership. These efforts explicitly aimed to challenge the established mental models of decision makers. Although the company initially succeeded in sustaining its leadership, eventually, it declined dramatically. Thus, the case of Nokia represents a compelling setting to investigate our research question regarding the relationship among analogical reasoning, cognition, and long-term performance.

\subsection{Data collection}

The focal period of interest for our longitudinal study is from 1998 to 2016 . The study period starts in 1998, when Nokia became the global leader among $2 \mathrm{G}$ handset makers and the first precommercial 3G network was launched, and ends in 2016, when Nokia's mobile phone business division was finally dismantled by Microsoft — after Microsoft itself had acquired it in 2014. Data collection began in 2002 and encompassed the following topics: i) Nokia's strategic 
decision-making processes; ii) managerial beliefs; iii) investment decisions; and iv) performance (market share, sales and profits).

Our research question shaped our data collection plan and process. This process was iterative, stopping when a level of saturation was reached (Glaser and Strauss, 1967), and relied on two primary data sources: archives and interviews. We first gathered extensive archival data from both internal and external sources. Internal sources included press releases, annual reports and business reviews, internal reports and presentations, organizational charts, and video and audio archives of presentations made by the firm's executives at public conferences and meetings or at product launch events. External sources included prior studies of Nokia's history and business press articles about both Nokia and its main competitors selected via ABI/INFORM, complemented with analyst reports (Aspara et al., 2013; Doz and Kosonen, 2008). External sources also included high-tech magazines and specialized websites that covered the evolution of the mobile communication industry throughout the 2000s and 2010s. Finally, leading research and consulting firms such as Gartner and International Data Corporation (IDC) provided extensive data about the worldwide sales and market shares of Nokia and its rivals. Overall, the archival data included more than 18,000 pages of documentation and 60 videos. Our second main data source was interviews with internal and external informants. The interviews were semi-structured, as they were open-ended but based on a common set of questions about strategic decision-making processes and managerial assumptions regarding the future evolution of the mobile communication business. The internal informants were business executives who were selected according to their tenure and involvement in the strategic decisionmaking processes of the firm. In particular, we interviewed the senior managers in charge of designing and coordinating environmental scanning and technology roadmapping at Nokia, 
corporate planners, $\mathrm{R} \& \mathrm{D}$ and product innovation managers, and executive directors. The external informants were business partners, industry experts, and consultants selected according to their direct involvement with and knowledge of the company. The use of multiple internal and external informants mitigates the potential biases of any individual respondent, while the combination of archival sources and interviews enables a rich, triangulated and relatively accurate exploration of the phenomena under study (Kumar et al.,1993).

In total, we conducted 34 interviews. The interviews generally lasted from one to two hours and were conducted between 2002 and 2011.

\subsection{Data analysis}

The data analysis used the traditional approaches for case study research (Bettis et al., 2015; Eisenhardt et al., 2016; Locke, 2001; Yin, 2003). The data analysis and data collection proceeded in a highly iterative way as new data were used to test the robustness of our emerging interpretations of the relationship between analogical reasoning and cognition.

Our research question (How does analogical reasoning affect cognition and investment decisions in the face of technological discontinuities?) guided the prioritization of the analytical process. During the early stage, we carefully examined our informants' data and aimed to produce a rich description of their decision-making processes, emerging managerial beliefs, and strategic investments. According to the prescriptions for grounded-theory building, the data were content analyzed to search for emerging codes and categories (Charmaz, 2006; Locke, 2001; Strauss and Corbin, 1990). The codes and categories were labeled in terms that were close to the words that were actually used by Nokia's executives, especially our informants, when expressing their beliefs about the likely evolution of the mobile phone industry. These beliefs and their 
relationship with analogical reasoning processes resulted from our data in the form of forwardlooking statements introduced by words and phrases, such as "according to our WorldMap", "according to our roadmaps" (we illustrate both Nokia's roadmaps and WorldMap in the following section), "our future business will be", "we believe", "we foresee", and "we assume". The coding process was highly iterative. In the first round of data analysis, codes were used to emphasize basic beliefs about future changes in technologies, markets and competitors, products and product features. Subsequent rounds of data analysis helped us to categorize the basic codes and group them in macro codes to illustrate the beliefs of Nokia's managers about future sources of success in the mobile communication business and the barriers to these sources. These beliefs are described in the next sections of the paper and summarized in Fig. 1. The coding process evolved through constant comparison and occurred on two levels, namely, within each interview and official document, which helped identify emerging beliefs, and across interviews and official documents, which helped identify the recurrence and strength of these beliefs.

Following past research on cognition and strategic decision-making (e.g., Camerer and Lovallo, 1999: Laamanen and Wallin, 2009; Simon and Houghton, 2003), we checked the consistency between managerial assumptions and investment decisions in new technological skills, marketing and production resources, products and product features. We also tracked the timing of these decisions and compared them with the timing of the decisions of other mobile phone manufacturers. Furthermore, following past research on strategy making and cognition (e.g., de Geus, 1988; Phadnis et al., 2015), we contrasted the emerging assumptions of Nokia's managers with their previous individual and organizational experiences. We thus checked whether these assumptions were either consistent with the prior history of the company or 
represented a discontinuity instead. These different levels of investigation helped us to assess the confidence of Nokia's managers in their emerging assumptions about the future and the ultimate role of these assumptions in directing their investment decisions.

In each step of collecting and analyzing the data, we used tables and memos to summarize our main findings and early interpretations and to track and develop our emerging insights. We then followed an iterative process of cycling among the data, emerging theory, and literature to refine our central constructs and theoretical propositions, relate them to existing theories, and clarify our contributions.

\section{Technological change and analogical reasoning at Nokia}

Beginning in the late 1990 s, Nokia established a systematic approach to investigating technological and market changes, anticipating their likely evolution and impact, and integrating forecasts into operations. Strategic decision-making efforts were coordinated by a corporate planning unit, involved a wide network of partners, suppliers, customers, and consultants, and extensively used analogical reasoning.

The main aim of these efforts was to change the established mental models of top executives by providing fresh new insights and knowledge that extended beyond the idiosyncratic history of Nokia and the mobile phone industry. A specific team was tasked with diligently investigating all different sectors within the broadly defined Information and Communication Technology (ICT) business, especially those sectors that had already experienced the advent of the Internet and digital technologies, i.e., the PC, imaging, game, and music industries. Then, Nokia's executives used these different industries as source problems for analogical reasoning to anticipate the likely impact of the Internet and digital technologies on 
their mobile communication industry (target problem). A senior manager explained to us as follows:

One of the main output of our foresight approach is the Nokia WorldMap, which we deliver on a yearly basis. The Nokia WorldMap compiles those trends and disruptions in the Converging Digital Industry and related macro environment that are of highest potential impact to Nokia in the next five years. ${ }^{1}$

We seek to combine business, technology, and user perspectives to provide trend and disruption input to the strategy process; challenge widely held orthodoxies in Nokia; raise cross-functional awareness of important trends and disruptions across the company; stimulate out-of-the-box thinking and strategic dialogue; and identify new business opportunities.

We collect market data and rely on external sources like business experts, consultants, and academics to bring unique insight and foresight on topics that drive the renewal of Nokia. We learn from the impact of disruptive technologies on different market areas and organizations within the broadly defined ICT business, like hardware manufacturers in the $P C$ industry and the imaging industry.

Our target audience are Nokia's top decision makers, planners and participants in Nokia strategy work, roadmappers and other future-oriented employees. We involve top managers in the future exploration process itself to understand the underlying drivers and implications needed for decision making. Changes in mental models can only be achieved via a process of cocreation [emphasis added].

The key findings of the investigation of the broad ICT industry were summarized in the Nokia WorldMap, which is a document listing the most relevant drivers of change in technologies, customer needs, and competitive dynamics able to affect Nokia and the mobile phone business. The Nokia WorldMap was regularly updated and further elaborated through product and technology roadmaps, which helped Nokia's managers make their emerging assumptions about the future explicit and share these assumptions across the company. ${ }^{2}$

\footnotetext{
${ }^{1}$ The concept of disruptive innovation was originally introduced by Christensen (1997).

${ }^{2}$ Product and technology roadmaps are graphical representations of interconnected nodes of the co-evolution of technologies, products and markets over time (Phaal et al., 2004).
} 
The roadmaps consisted of different layers; at the top level, the roadmaps were primarily graphic and included hypotheses regarding future product features, market segments, suppliers and competitors. Below the top level, roadmaps involved more detailed analyses and documents, typically a spreadsheet that further explored future market segments, competitors, and product features. The deepest level of the roadmaps consisted of text documents describing the future industry value chain, competitors, technology trends, and resources (e.g., marketing and manufacturing assets) required for sustaining the leadership of the company. Remarkably, the model number of each device that Nokia made throughout the 2000s was designated around an entire scheme that fit into its overall product roadmap. As a senior manager illustrated,

Roadmapping is Nokia's plan. It's a living document. Our roadmaps are our future and how we define it.

\section{Beliefs and investment decisions}

The diligent scanning of the PC, imaging, game, and music businesses and the use of these industries as source problems for analogical reasoning informed some new beliefs, which indeed disrupted the established mental models ("widely held orthodoxies") of Nokia's managers. These new beliefs regarded i) the crucial role of the software operating system in the differentiation of future $3 \mathrm{G}$ handsets and ii) the decline of traditional voice- and text-based phones and the rise of completely new product categories.

These beliefs had a profound impact on the investments that Nokia made beginning in the late 1990s in relation to technological skills, production and marketing assets, and products. We frame the description of these investment decisions around three main periods that marked the evolution of the competitive position of the company: 1) from the 1998 to 2003, when the company introduced its first 3G-based disruptive product categories; 2) from 2004 to 2008, when 
Nokia withdrew its early product categories and launched its new smartphone products; and 3) from 2009 to 2014, when Google and Apple entered the smartphone business and finally prompted the exit of Nokia.

5.1. Analogical reasoning, managerial beliefs, and investment decisions: 1998 to 2003

Operating system. A new managerial belief informed by analogical reasoning at Nokia beginning in the late 1990s was that future success would originate from software applications.

The 1999 Annual Report emphasized this as follows:

Most of the new services, features and functions will be based on software-and much of it user-configurable. Software will play an increasingly important role in the coming years. That's why we are taking a leading role in the development of software platforms [...] for future mobile devices.

The way we interact and communicate is entering a new era of exciting possibilities and opportunities. We are entering the era of the Mobile Information Society. An era of anything, anytime, anywhere. An era of unprecedented freedom. And the mobile phone is at the center of this revolution. [...] We believe the mobile phone is the natural vehicle for putting the Internet into everybody's pocket.

In particular, analogical reasoning informed the strategic assumption that without differentiating the operating system, Nokia would ultimately not be able to differentiate its $3 \mathrm{G}$ handsets from the handsets of other manufacturers. This disruptive assumption was the result of the analogy with previous competition outcomes in the PC industry in which the Internet had already become a widespread reality in the late 1990s. Mobile Internet required forthcoming 3Ghandsets to run an operating system similar to that of PCs; this meant that Microsoft had the concrete possibility of entering the business and establishing its software platform for mobile handsets, just as it had done with Windows for PCs. In such a case, 3G handsets would likely become commodities - exactly like personal computers. A senior manager of Nokia explained to 
us as follows:

Our roadmaps indicate that we are going to face increased competition from software companies. We believe this is the case in particular of Microsoft, that has the opportunity to do in the mobile handset market what it did in the PC industry where, after the establishment of its Windows standard, hardware has become a commodity and Microsoft itself is taking most of the profits. That's what we want to prevent as a mobile device manufacturer - we don't want to go the way of the PC business.

Another manager commented,

The main issue with Microsoft's Windows software is that it is a proprietary standard: PC makers do not have access to the source code. They cannot change the operating system and thereby they cannot provide different features, applications and user interfaces. That's why we need to control the operating system running on our devices: we need to differentiate our devices from the ones of other manufacturers. Product differentiation creates value not only for handset makers but also for customers that can choose among a wide array of solutions.

The 1998 Annual Report emphasized,

Nokia will continue to introduce solutions and products based on non-proprietary standards and technologies in 1999 and beyond.

The new managerial belief about the essential role of the operating system in product differentiation had a direct impact upon the investment decisions of Nokia's managers. In the late 1990s, together with Ericsson, Motorola, and other leading manufacturers, Nokia's managers established Symbian, a software licensing company whose mission was to develop the Symbian operating system (OS) for $3 \mathrm{G}$ mobile devices. The Symbian OS was an open platform that gave licensees access to the underlying software code so that they could modify the operating system itself and provide differentiated solutions on their own handsets, especially on-screen menus and graphics (user interfaces). However, software developers could easily port their applications on any Symbian-based device, regardless of the manufacturer. As a non-proprietary system, Symbian was thus expected to boost innovation from independent software producers as well as provide 
consumers with a wide and varied selection of competitive, yet interoperable products and services (Nokia 2001Annual Report).

In 2001, Nokia established its Mobile Software Unit and, in 2002, launched the Series 60 Symbian-based user interface, which it licensed to other handset makers, such as Siemens, Samsung and Panasonic.

The decisions to establish Symbian as an open platform and to license the Series 60 user interface were fully aligned with the lessons that Nokia's managers had learnt from previous competition outcomes in the PC industry. As Niklas Savander, vice president of the Nokia Mobile Software Unit, explained,

the long-term goal of the company is to have $30 \%$ to $40 \%$ of a very large market [i.e., a market where Symbian was the dominant platform] rather than to have 50\% to $60 \%$ of a smaller market. ${ }^{3}$

Specifically, Nokia's managers tried not to go the same way as Apple, who, after making its Mac OS operating system a proprietary standard, relegated its Macintosh computers to a small market niche. At the same time, by controlling the source code of Symbian, Nokia still guaranteed itself the opportunity to customize the software running on its devices and ultimately, to differentiate its devices.

New product categories. Another managerial belief informed by analogical reasoning in the late 1990s was that digital technologies would generate completely new product categories and disrupt traditional (2G) voice- and text-based phones. The Nokia 2001 Annual Report illustrated this belief:

3 Pringle, D. 2001. Symbian gets a boost from Nokia in its software battle with Microsoft. Wall Street Journal. November 22. Available at: http://www.wsj.com/articles/SB1005686785467738840. 
Technologies such as Java, XHTML, packet switching and multimedia messaging are becoming a tangible reality in the form of new product categories and concepts. Devices now coming on stream include imaging phones that also have cameras as well as phones that work as music players or game consoles. We believe these devices are contributing to the creation of entirely new communications markets.

This new belief originated from the analogy between the impact of digital technologies on the mobile phone industry and the impact of these same technologies on the imaging, music, and game industries, where they had already disrupted the mainstream products and product features of such incumbent firms as Eastman Kodak. A senior manager commented as follows in the early 2000s:

Internet, multimedia contents, music, imaging, games, and business applications like emails: by merging with mobile communication, each digital function represents the opportunity for a new product category. These disruptive technologies will drive the renewal of mobile phones as they did exactly with traditional cameras, music players, and game consoles. We are going to have cell phones which work as a sort of iPod, capable of downloading, saving and playing thousands of songs; cell phones which work as cameras; mobile phones for playing games against other phone users; and cell phones as Internet terminals.

The new belief about the disruption of traditional voice- and text-centered phones led Nokia to deeply change its product models and features. The 2001 Annual Report illustrated,

Our value-adding strategy for continued market leadership is the ongoing addition of new features and functionality to our phones. This means introducing new models within existing product categories while at the same time developing entirely new categories.

In 2003 , the company launched i) the Nokia 6600 , a hybrid device that combined a phone with an advanced camera to enable users to take and immediately share high-quality pictures; ii) the Nokia N-Gage, a hybrid device that combined a mobile phone with a game console to enable users to play games against one another via Bluetooth or over the Internet; and iii) the Nokia 3300 , a hybrid device that combined a mobile phone with a fully integrated digital music player and a stereo FM radio. All of these products were based on the Symbian operating system and 
represented remarkable breakthroughs in product design: they were larger and heavier than traditional mobile phones and featured larger screens and innovative shapes that required users to hold them horizontally rather than vertically. In 2003, the company also announced the Nokia 7700, a multimedia hybrid device optimized for web browsing and TV broadcasting.

Overall, Nokia introduced a new product model/category (hereafter, the "hybrid model") for each specific digital function. In the 2003 Nokia Capital Market Day, Vice President Anssi Vanjoki introduced the terms "game phones", "music phones", "imaging phones", and "media phones" to label these "entirely new product categories". ${ }^{4}$ The 2003 annual report illustrated their role in the whole product roadmap of the company:

Nokia's product matrix has six style dimensions (basic, expression, active, classic, fashion and premium) and five functional dimensions (voice, entertainment [i.e., music and games], media, imaging and business applications). By combining each of the styles with each of the functionalities, we should be increasingly able to address specific user needs. We believe for the different models to be successful, they need to be differentiated from one another by optimizing them for their primary usage [i.e., functional dimension].

\subsection{Analogical reasoning, managerial beliefs, and investment decisions: 2004 to 2008}

Contrary to Nokia's forecasts, mainstream customers rejected its disruptive hybrid models and favored instead rivals' $3 \mathrm{G}$ products, which integrated different digital features such as color screens, a camera, and music. In the first half of 2004, Nokia consequently suffered a significant decline in sales and profits, with its market share decreasing to $29 \%$ from an average of $35 \%$ over the previous three years. Olii-Pekka Kallasvuo, head of the Nokia Mobile Phone division, admitted that "We definitely had gaps in our product portfolio". CEO Jorma Ollila agreed that

\footnotetext{
${ }^{4}$ Nokia Capital Market Day was an event held annually throughout the 2000s during which Nokia's top managers presented their strategy for future growth to financial investors.
} 
the company had failed to anticipate the market evolution and product demand of traditional customers. 5

However, the response of Nokia's managers was quick and bold. In 2004, they discontinued — only a few months after their release - the 3300 and 6600 hybrid models and cancelled the launch of the 7700 handset. Contextually, they switched the focus of their roadmaps to a completely new type of product category that combined, in the same device, all digital functions and Internet applications. In the 2004 annual report, Nokia's managers used for the first time the word "smartphones" to introduce this new product category:

a smartphone is a new category of mobile device that can run computer-like applications such as email, web browsing and enterprise software and can also have built-in music players, video recorders and other multimedia features.

In 2005, they launched the brand-new Nseries family of smartphones. Anssi Vanjoki-the same top executive who in 2003 had directed the launch of Nokia's hybrid models - described the Nseries as follows:

The Nokia Nseries brings mobility to those experiences which used to be linked to a place or a single purpose device. This next step in digital convergence brings together mobile devices, Internet content, still and video cameras, music, email and much more. Nokia Nseries devices share similar design traits as mobile phones, but they are actually powerful pocketable computers with a comprehensive set of multimedia features. ${ }^{6}$

The smartphones of the Nseries family clearly differed from the early hybrid models of the company. However, these smartphones similarly aimed to disrupt traditional voice- and textbased phones, and therefore, their development was still fully consistent with the belief regarding

\footnotetext{
5 The Economist. 2005. The giant in the palm of your hand. February, 10. Available at: http://www.economist.com/node/3644543.

${ }^{6}$ Nokia drives Internet Convergence with new Nokia Nseries devices and experiences. 2006. Nokia Center press release, April 25.
} 
the rise of new product categories, i.e., a belief originally informed by strategy making and analogical reasoning in the late 1990s. In 2004 and 2005, the Nokia Annual Reports continued to emphasize this belief as follows:

The mobile device market is expanding from voice-based communications towards new, data-driven areas and applications in consumer multimedia and enterprise mobility solutions (Nokia 2004 Annual Report).

The mobile communications market is dynamic, new vocabulary is emerging and definitions are changing. This is in line with the introduction of entirely new products and product categories (Nokia 2005 Annual Report).

Between 2005 and 2008, Nokia launched more than 20 Nseries models. All of them were based on the Symbian operating system, which Nokia wholly controlled after it acquired the Symbian company in 2008. In the same years, Nokia released an updated edition of the Symbian-based Series 60 user interface, which was renamed the S60, and developed innovative software applications, such as maps, games, instant messaging, and an ad hoc interface (the "PC suite"), to connect smartphones to PCs. The company also launched the OVI online store, through which customers could access their favorite smartphone applications altogether.

Thanks to these new investment decisions, Nokia established its leadership in the emerging smartphone market, with a share of almost 50\% in 2007 and 2008.

\subsection{Analogical reasoning, managerial beliefs, and investment decisions: 2009 to 2016}

In the late 2000s, the growing popularity of smartphones and mobile Internet prompted the entry of two new major players, i.e., Apple, which introduced its iPhone and its iOS software operating system for mobile devices in 2007, and Google, which released its Android operating system in 2008. Both challengers offered an alternative to Nokia's Symbian. Whereas iOS was a proprietary standard that Apple employed only in its iPhone models, Google made Android 
available to any manufacturer.

As they entered the smartphone market, Apple and Google brought with them the software skills and wide networks of application providers they had formerly developed in the PC industry. These networks allowed both companies to provide customers with a wide range of innovative applications ("apps") that greatly enhanced their mobile Internet experience. By the end of 2010, Google offered more than 100,000 apps in its "Android Market", and Apple offered more than 300,000 in its "App Store"; in contrast, only 20,000 apps were available for Symbian. The sales of Apple's iPhones and Android-based smartphones (by manufacturers such as Samsung, HTC, and Motorola) literally boomed, to the detriment of Nokia.

In response to the decline of Symbian, Nokia partnered with Intel in 2010 to create the new MeeGo operating system. However, since the development of MeeGo was proceeding slowly, in February 2011, Nokia dismissed both Symbian and MeeGo and embraced Microsoft's Windows Phone as its new smartphone platform. The Nokia 2011 Annual Report illustrates the rationale for this partnership as follows:

Certain smartphone platforms and their related ecosystems have gained significant momentum and market share, specifically Apple's iOS platform and Google's Android platform, and are continuing apace, with Android-based smartphones increasingly gaining market share at lower price points. In February 2011, we announced our partnership with Microsoft to bring together our respective complementary assets and expertise to build a new global mobile ecosystem for smartphones (the "Microsoft partnership"). Under the Microsoft partnership, formalized in April 2011, we are adopting, and are licensing from Microsoft, Windows Phone as our primary smartphone platform.

By joining Microsoft, Nokia aimed to co-develop a new operating system that, similarly to Symbian, could allow the company to set its smartphones apart from those of other manufacturers, especially those that were using Android. The decision to embrace Windows Phone was therefore still fully consistent with the managerial belief about the essential role of 
the operating system in product differentiation - a belief which strategy making and analogical reasoning originally informed in the late 1990s. The 2011Annual Report continued to emphasize this belief as follows:

The market for smartphones has shifted from a device oriented strategy to a platform [software operating system] oriented strategy. Today, industry participants are creating competing ecosystems of mutually beneficial partnerships to combine hardware, software, services and an application environment to create high-quality differentiated smartphones.

The first Nokia smartphones with Windows Phone were introduced in October 2011, under the new Lumia brand. However, after the launch of the Lumia family, Android-based manufacturers consistently increased their sales, with Samsung becoming the new market leader - together with Apple — and Nokia's market share being relegated to a small niche that reached the peak of $3 \%$ in the $3^{\text {rd }}$ quarter of 2013. Samsung, in particular, despite being unable to differentiate its operating system and applications from the operating system and applications of other Android-based manufacturers, succeeded over these manufacturers because of other sources of differentiation such as design, brand recognition, hardware performance (e.g., display resolution and shape), array of models and time to market. ${ }^{7}$

On the one hand, Nokia's Lumia models were also outstanding in terms of design and hardware features: for instance, the Lumia 1020, introduced in July 2013, featured a 41 MP (megapixel) camera, which was unrivaled at the time. On the other hand, the enduring lack of apps from software developers doomed customers' interest in Windows Phone and ultimately in

7 Hirur, S. 2012. Samsung Emerges Clear Leader in Android Smartphone Market; International Business Times, May 19. Available at: http://www.ibtimes.co.uk/samsung-rule-android-smartphone-galaxy-s3-sales-342946; Grobart, S. 2013. How Samsung became the No. 1 Smartphone maker. Bloomberg, March 29. Available at: http://www.bloomberg.com/news/articles/2013-03-28/how-samsung-became-the-worlds-no-dot-1-smartphonemaker. 
the Lumia series: in 2013, Windows Phone featured 130,000 apps compared with the 1,100,000 available for Apple's iOS and the 1,000,000 apps running on Android.

Because of the weakening of its financial position, in September 2013, Nokia sold its smartphone business to Microsoft. After the acquisition was finalized in April 2014, the sales of Lumia smartphones continued to stall, and Microsoft eventually decided to discontinue them in 2016.

\section{A framework of analogical reasoning, cognition, and the response to technological change}

Fig. 1 summarizes our findings from the case study of Nokia regarding the evolution of analogical reasoning, beliefs, and investment decisions.

\section{"Insert Fig. 1 about here"}

On the one hand, between 2003 and 2008 the company managed to sustain its leadership and actually increased its profits and market share, especially in the emerging smartphone market. On the other hand, Nokia failed later on to cope with the entry of Apple and Google and eventually quit the smartphone market. Overall, our findings offer an emerging conceptual framework of the relationship among analogical reasoning, cognitive processes of attention and interpretation, and organizational performance in the face of technological change.

\subsection{Analogy and cognition}

As they faced the advent of digital technologies (in particular, digital imaging, game, and music: in the remainder of the paper we use the term "digital technologies" to refer to these 
technologies) and the Internet, Nokia's managers identified these discontinuities as the main drivers of future success or decline. Such identification was the premise for analogical reasoning: digital technologies and the Internet represented the relevant features (structural relations) that characterized the future leadership of the mobile phone industry (target problem). Nokia's managers then thoroughly scanned the broad ICT business to retrieve other industries (source problem) that had previously shared the same structural relations: they eventually selected the imaging industry (which had already experienced the advent of digital imaging), the music industry (digital music), the game industry (digital gaming) and the PC industry (Internet). Nokia's managers explored the success or decline of incumbent firms in these industries and drew deep similarities between the historical impact of digital technologies and the Internet on such incumbent firms and the future impact of the same technologies on mobile phone manufacturers.

The insights from these analogies took the form of solutions (sources of success in the changing mobile phone industry) and warnings (barriers to success) that were encoded in the emerging beliefs of Nokia managers_-beliefs that represented strong discontinuities from the history of Nokia and the entire mobile phone business under the previous $2 \mathrm{G}$ technological paradigm. Product and technology roadmaps contributed to the articulation and establishment of these discontinuous beliefs. This is the case for both the new belief regarding the emergence of disruptive product categories — as opposed to traditional text- and voice-based phones — and the new belief regarding the essential role of the operating system in product differentiation —as opposed to the historical sources of differentiation of mobile phones, such as product design or hardware features.

In particular, the belief about the rise of disruptive product categories was informed by the 
insights gained from the game, imaging, and music industries. Nokia's managers noticed that, in these industries (source problems), digital technologies (shared structural relations) had prompted the reduction of traditional products and services, the entry of new players, and ultimately, the decline of incumbent firms such as Eastman Kodak which were not quick enough to redesign their products, product features, and business models. These lessons were used to make inferences about the implications of digital technologies for mobile phone manufacturers (target problem) and were ultimately encoded in the new belief about the disruption of traditional handsets.

The new belief that mobile phone makers would not be able to differentiate their devices without differentiating the operating system originated instead from the insights that Nokia's managers gained from the PC industry. In the early 1990s, the incumbent firms of this industry (source problem) had already experienced the advent of Internet (shared structural relation) and suffered from a sharp decline in profit after the establishment of Microsoft's Windows. This lesson was used for making inferences about the likely impact of the Internet on mobile phone manufacturers (target problem) and was ultimately encoded in the new belief about the essential role of the operating system in the differentiation vs. commoditization of mobile phones. To fully appreciate the cognitive discontinuity that was inherent in this new belief, it is worth emphasizing that when this belief originally emerged in the late 1990s, Nokia's top executives had already been with the company for a long time; none of them had held an executive position at any PC firm. More importantly, all of the $2 \mathrm{G}$ mobile phones that Nokia had delivered until then featured a relatively simple user interface and did not use any operating system; the success of these $2 \mathrm{G}$ devices was based instead on the sources of differentiation of product design, time to market, array of products, brand recognition, and hardware features (Doz and Kosonen, 2008; 
Steinbeck, 2001).

Given the influence of their prior history, Nokia's managers likely believed that the successful differentiation of $3 \mathrm{G}$ handsets would come from the same competitive factors of product design, hardware features, etc. However, analogical reasoning led Nokia's managers to focus their attention on the history of the PC industry rather than on their own mobile phone industry and on the role of the operating system in product differentiation rather than on the traditional drivers of success related to $2 \mathrm{G}$ handsets.

Overall, our findings from the case of Nokia suggest that when managers face technological discontinuities, they are likely to scan their external environment and search for other industries that have already experienced the same technologies. Our findings also suggest that managers are likely to use these different industries as a source problem for analogical reasoning and that analogical reasoning is likely to help managers evolve their mental models, by enabling the rise of new beliefs that depart from the prior history of their company and industry.

\subsection{Analogy, cognitive attention and interpretation, overconfidence, and inertia}

The new beliefs informed by analogical reasoning beginning in the late 1990s, i.e., the beliefs regarding the prominent role of the operating system and the rise of new product categories, emerged as the new dominant logic that guided the key investment decisions of Nokia's managers in their fast-paced business. These beliefs became deeply rooted, and despite negative market feedback on Nokia's early products, they continued to direct the cognitive processes of attention and interpretation of Nokia's managers for more than a decade, until the company finally quit the mobile phone market.

In particular, the belief about the rise of disruptive product categories first led Nokia to 
introduce its hybrid models (i.e., Nokia N-Gage, 7700, 6600, and 3300) in 2003. When customers rejected these models, Nokia's managers continued to firmly hold the same belief which continued to direct their investment decisions. In the mid-2000s, the company's Annual Reports constantly emphasized that new product categories would emerge and disrupt traditional voice- and text-based phones (see the quotes in the previous section). Consistent with this strategic assumption, in 2005, Nokia was the first mobile phone manufacturer to launch a brandnew family of smartphones, i.e., the Nseries.

The belief about the essential role of the operating system in product differentiation had an even stronger and longer-lasting influence on strategic investment decisions. This belief initially led Nokia's managers to invest in the development of the Symbian open platform in the late 1990s. Afterwards, when the market share of Symbian started to drop in 2010, this belief survived the failure of Symbian itself and continued to direct the cognitive processes through which Nokia's managers identified and evaluated the alternative options available for their next software platform. Nokia's managers turned out to be overconfident in their belief about the essential role of the operating system in product differentiation and this overconfidence eventually increased organizational inertia.

Specifically, when they dismissed Symbian and had to choose between Windows Phone and Android, Nokia's managers still focused their attention on the potential to differentiate their software platform. Such a focus clearly emerges from what the top executives of the company had to say on the final decision to embrace Windows Phone. According to Nokia CEO Stephen Elop, "We spent time with our colleagues at Google and explored the Google [Android] 
ecosystem, but we felt we would have difficulty differentiating within that ecosystem". ${ }^{8}$ Nokia's

managers were persuaded that they could not change Android sufficiently deeply to differentiate their devices from those of other companies using the same platform. By partnering with Microsoft instead, Nokia gave itself the opportunity to access the Windows Phone code and customize it. In the 2011 Annual Report, top executives emphasized the following:

Although Microsoft will continue to license Windows Phone to other mobile manufacturers, the Microsoft partnership allows us to customize the Windows Phone platform with a view to differentiating Nokia smartphones from those of our competitors that also use the Windows Phone platform.

Our future success in the smartphone market [depends on] our ability to introduce and bring to market quantities of attractive, competitively priced Nokia products with Windows Phone that are positively differentiated from our competitors' products, both outside and within the Windows Phone ecosystem [emphasis added].

The belief about the essential role of the operating system in product differentiation also directed Nokia's managers' interpretation of the risks inherent in Windows Phone (vs. Android). When they signed the deal with Microsoft, Windows Phone was relegated to a mere $2 \%$ market niche. In the 2011 Annual Report, Nokia's own executives emphasized the challenge "to make Nokia products with Windows Phone a competitive choice for consumers" and to thus create a "global ecosystem for Windows Phone smartphones that achieves sufficient scale, value and attractiveness to all market participants". The manufacturing, marketing, and technological investments that Nokia was going to make in Windows Phone would clearly be irreversible and valueless if this platform failed.

However, Nokia's managers interpreted a partnership with Google as being even more

${ }^{8}$ BBC News. 2011. Nokia and Microsoft form partnership. February 11. Available at: http://www.bbc.co.uk/news/business-12427680. 
challenging and risky. Vice president Anssi Vanjoki compared handset makers using Android to Finnish boys "who pee in their pants" for warmth during the cold winter: these manufacturers were likely to enjoy only temporary relief because in the long run, they could not differentiate their products from rivals using the same operating system. ${ }^{9}$ Vanjoki emphasized that by embracing Android, Nokia

would become a commoditised box-maker like Dell, scrapping for market share with rivals that all use Android and so seem more or less the same. ${ }^{10}$

According to Nokia Chairman Jorma Ollila, the board of directors was unanimous when they chose Windows Phone over Android. ${ }^{11}$

However, later on, the success of Samsung's partnership with Android clearly showed that the PC industry and the mobile phone industry were not structurally aligned and the analogy between these industries was not effective. Specifically, the drivers of differentiation of mobile phones were more numerous and varied than those of PCs and included, beyond the operating system, product design, time to market, array of products, and hardware features. Nokia's managers based the identification of their source problem for analogical reasoning on the new technology that would affect their mobile phone industry: the Internet was the overriding structural relation they took into consideration when the selected the source problem of the PC industry. By doing so, they overlooked the other and different drivers of competition (and thereby the other structural relations) that governed the different ways the mobile phone and the

${ }^{9}$ Financial Times. 2010. Nokia set to strike back at Android. September 14.

${ }^{10}$ Financial Times. 2010. Nokia. September 21.

11 Sajari, P. 2013. Jorma Ollila feels grief over sale of Nokia phones - admits to mistakes. Hesingin Sanomat, October 17. Available at: http://www.hs.fi/m/talous/a1381973653499. 
PC industries worked.

As a result, Nokia's managers' confidence in their assumption about the ultimate role of the operating system in product differentiation exceeded the real accuracy of this assumption (i.e., overconfidence) and this overconfidence led the company to bet its future on only one option (Windows Phone) rather than experimenting with both Windows Phone and Android—as Samsung did. (Beginning in the late 1990s, Samsung actually experimented with all of the alternative platforms that became available, i.e., Symbian and the Nokia's Series 60 user interface, Microsoft's Windows Phone, Google's Android, and its own Bada. Even in 2013 and 2014, despite Android's clear market dominance, Samsung continued to develop some Windows Phone-based smartphone models.)

In 2014, when Nokia's managers realized that Windows Phone was not a valuable alternative to Android and that Samsung could differentiate its products even without a distinctive operating system, it was too late to shift to Android and emerge within this ecosystem. Nokia's managers were left with no other choice than to sell the mobile phone business to Microsoft. Remarkably, Samsung based its success over other Android-based manufacturers on the different sources of differentiation - product design, array of products, hardware features, brand recognition, and time to market—-that had been the main drivers of Nokia's leadership within the previous $2 \mathrm{G}$ technological paradigm. Nokia's managers' overconfidence in their new assumption about the essential role of the operating system ultimately turned into a source of inertia that contributed to the decline of the company instead of to the sustainability of its competitive advantage.

Fig. 2 summarizes our empirical evidence from Nokia regarding the relationship among the analogical reasoning, managerial attention and interpretation, and technology competition 
outcomes.

\section{"Insert Fig. 2 about here"}

Overall, our findings suggest that when managers face a new technology and use other industries that have already experienced the same technology as a source problem for analogical reasoning, these managers are likely to develop new beliefs that become dominant and direct their strategic investment decisions. Our findings also suggest that when managers focus on the new technology as the main similarity (structural relation) between other industries and their own industry and overlook other drivers of competition, these managers are likely to become overconfident in their new beliefs and this overconfidence is likely to lead to organizational inertia.

\section{Discussion}

In this paper, we contribute to our understanding of analogy and cognitive dynamics in the face of technological discontinuities. Our core contribution is a conceptual framework that illustrates the effects of analogical reasoning on the cognitive processes of attention and interpretation. We respond to the question of how managerial beliefs originate and develop over time and how they influence strategic investment decisions (Kaplan and Tripsas 2008; Tripsas and Gavetti, 2000). More generally, we expand our understanding of the long-term performance of firms in turbulent environments (Teece, 2007).

\subsection{Analogy and managerial cognition}

The first contribution of our work is related to the research stream of managerial cognition. 
Scholars have traditionally emphasized the role of the prior history of decision makers (including their idiosyncratic organizational experiences and industry affiliations) in informing their mental models (Prahalad and Bettis, 1986; Barr et al., 1992; Kaplan, 2008b). We expand this work by examining the role of analogical reasoning in informing managerial beliefs (Gary et al., 2012; Gavetti et al., 2005; Gilboa and Schmeidler, 2001; Loewenstein et al., 2003).

By adopting a longitudinal perspective, we show that analogical reasoning at Nokia contributed to the renewal of the mental models that managers had developed through their idiosyncratic experiences at this company. Nokia's managers explored the history of other companies and industries that had already faced the same technological discontinuities that they were going to face, and they drew strong similarities between such industries (source problem) and their industry (target problem). The novel beliefs that originated from analogical reasoning became deeply rooted and finally emerged as the new dominant logic that directed the key investment decisions at Nokia for more than a decade, namely, from the late 1990s to the mid2010s.

In particular, our findings emphasize the cognitive discontinuity inherent in the new belief that the company could not differentiate its handsets without differentiating the operating system. This belief was derived from the previous history of the PC industry, as Nokia's managers adapted the lesson from the rise of Windows and the decline of computer manufacturers to find a solution to how they could prevent the standardization of their next 3G devices. This new belief disrupted the "widely held orthodoxies" about the sources of differentiation that Nokia had traditionally exploited under the previous $2 \mathrm{G}$ technology and guided its investment decisions from the development of Symbian to the adoption of Windows Phone.

The case of Nokia clearly shows that if we focus only on a company's prior history and do 
not investigate its strategy making efforts, especially analogical reasoning, we cannot fully understand the origin of managers' mental frames and their cognitive processes of attention and interpretation in the face of technological discontinuities. Future research efforts might build on our work to expand our understanding of the relationship between cognition and analogical reasoning in relation to the key questions of how managers search for analogies, evaluate their validity, and finally use them to address their target problem (Gavetti and Menon, 2016).

\subsection{Analogical reasoning, cognition, and performance}

By combining research concerning analogical reasoning and research concerning cognition, we add to our understanding of technology competition outcomes and, ultimately, adaptation and inertia in the face of technological change (Kaplan, 2008b; Tripsas and Gavetti, 2000). Our work underlines both the benefits and pitfalls that relate to the ability of analogical thinking to change the beliefs that managers inherit from their own history and the history of their own companies and industries.

On the one hand, the renewal of mental models might help managers to escape the myopia and inertia that result from their past experiences (Kaplan, 2008a; Porac et al., 1995). At Nokia, this was the case of the belief that new product categories would disrupt traditional voice- and text-based phones. The analogy between the imaging, game, and music industries, on the one hand, and the mobile phone industry, on the other hand, was based on structural relations. In all these industries, digital technologies opened the door to completely different product features, services, and rival firms; to sustain their leadership (and avoid the mistake of some incumbent camera or game console manufacturers), incumbent mobile phone manufacturers had to pioneer new products and markets and prevent the rise of new rivals. The belief that originated from this 
analogy therefore was accurate, i.e., consistent with future competition outcomes. Despite rejecting Nokia's early hybrid models in the early 2000s, mainstream customers started indeed to demand completely new devices with integrated digital features and Internet access: the belief about the rise of disruptive product categories contributed to the capability of Nokia's managers to notice and make sense of this emerging demand more quickly and better than rivals. Nokia was the first company to launch a brand-new family of smartphones in 2005, i.e., the Nseries, through which it achieved a significant first mover advantage over rivals all throughout the second half of the 2000s (with an approximate share of 50\% in the smartphone market).

However, if analogical reasoning fails to anticipate the main future sources of competitive advantage, the new beliefs that derive from analogical reasoning itself are likely to become a source of inertia rather than adaptation. This was the case of the analogy between the PC industry and the mobile phone industry and of the belief that the software operating system would be the main driver of product differentiation. The reasons for the historical struggles of PC manufacturers applied only partially to mobile phone manufacturers. Although PCs became commodities after the establishment of a dominant software platform, smartphones could still be differentiated because of hardware features, product design, brand and time to market. The analogy between the PC industry and the mobile phone industry therefore was not based on structural relations and the resulting belief about the prominent role of the operating system was not accurate, i.e., consistent with future competition outcomes. In 2010, this belief led Nokia to embrace Windows Phone instead of Android, despite the opportunity to establish itself within the Android ecosystem (at that time, Nokia was still the leading global smartphone manufacturer).

In this regard, previous scholars have emphasized that the resources (e.g., technological skills and assets) that firms develop according to their early strategic plans often become a major 
source of inertia (Liebermann and Montgomery, 1988; Mintzberg, 1990). Our findings build upon this work by expanding our knowledge about the ultimate reasons for organizational inertia. We show that firms can actually dismiss relatively easily the resources that they develop according to their early strategic plans and early entry in new markets. However, the same firms are less likely to dismiss the new managerial beliefs that arise from analogical thinking: these beliefs tend to become deeply rooted and have a long-lasting influence on cognitive attention and interpretation by continuing to direct the search process for the next organizational resources. The early beliefs that originate from analogical reasoning — not the early resources per se that managers develop according to their early entry in new markets - are therefore likely to become the most relevant source of inertia.

The case of Nokia provides a compelling example. By rejecting Symbian, i.e., their early operating system, in February 2011, Nokia's managers clearly demonstrated they were not locked into this operating system per se. Their reaction to market changes was actually prompt and bold: when Nokia's managers dismissed it, Symbian was still the most popular operating system. On the other hand, by partnering with Microsoft, Nokia's managers demonstrated that they were locked in the belief that was behind Symbian, i.e., the belief that the operating system was the key resource they had to control in order to eventually differentiate their handsets. This belief—rather than Symbian or Windows Phone per se—ultimately contributed to Nokia's decline.

\subsection{Managerial implications}

By shedding light on the relationship among analogy, cognition, and long-term performance, our work has relevant managerial implications for technology management (Hoisl et al., 2015; 
Nightingale, 2004; Porter et al., 2011).

Our findings show that decision makers have a concrete opportunity to use analogical reasoning to evolve their beliefs in a changing environment. Analogical reasoning can thus effectively contribute to the cognitive skills that are the foundations of strategic foresight (Gavetti and Menon, 2016) and dynamic capabilities (Teece, 2007). However, decision makers have the key task of understanding when a new technology represents the main similarity (structural relation) between their industry (target problem) and another industry that has already experienced the same technology (source problem), by distinguishing such a case from those in which there are actually different drivers of competition - beyond the new technology - that govern these industries. Consistent with the findings of previous scholars (Gary et al., 2012; Gavetti et al., 2005), while decision makers who perform this task effectively are likely to make analogies that lead to accurate beliefs (as in the case of Nokia's analogy between the imaging and the mobile phone industries and the belief about the rise of new product categories), managers who do not are likely to make analogies that lead to inaccurate beliefs instead (as in the case of the analogy between the PC industry and the mobile phone industry and the belief about the role of the operating system).

In this regard, previous scholars have emphasized that effective approaches to strategy making should combine analytical efforts with continuous experimentation (Eisenhardt and Sull, 2001; Grant, 2003). Our research builds on this work by strengthening the recommendation that managers experiment with different strategic plans instead of committing early to only one plan. Such experimentation could enable to make the distinction between structural and non-structural analogies and between accurate and inaccurate beliefs about future sources of competitive advantage. 
The opposite cases of Nokia and Samsung provide compelling evidence. Samsung experimented with different software platforms, whereas Nokia chose and committed very early to only one strategic plan. Consistent with previous findings from Camerer and Lovallo (1999) and Simon and Houghton (2003), Nokia's managers were overconfident in their assumptions about the future, in particular, their assumptions about the prominent role of the operating system in product differentiation. First, Nokia's managers committed to Symbian; later, they bet again the future of the company on only one option, i.e., Windows Phone. In contrast, by experimenting with alternative platforms and by embracing Android together with Windows Phone, Nokia's managers could have increased the flexibility of not only their assets-i.e., their operating systems — but also, most important, their beliefs about future drivers of differentiation.

\subsection{Opportunities for future research}

Analogical reasoning at Nokia was supported by environmental scanning and product and technology roadmapping. Future research efforts might explore different approaches to analogical reasoning and technological forecasting (Hoisl et al., 2015; Porter et al., 2011).

In particular, scholars and practitioners have emphasized the benefits of scenario planning in relation to organizational flexibility and learning (de Geus, 1988; Grant, 2003; Schoemaker, 1993). Similarly, the research about real options has shown that they provide an effective framework for the generation and evaluation of alternative investment plans (Smit and Trigeorgis, 2004; Tong and Reuer, 2007). We suggest that future research efforts focus on scenarios and real options as valuable approaches to analogical reasoning that foster the flexibility of not only strategic investments but also managers' mental models regarding the future sources of competitive advantages (Krychowski and Quelin, 2010; McGrath et al., 2004). 


\section{Conclusion}

The aim of this paper is to gain a holistic, longitudinal understanding of the co-evolution of analogical reasoning, managerial beliefs, and competition outcomes in a turbulent environment. We studied the exemplar case of a firm that had to address major technological changes.

Our research setting, data collection and data analysis were designed to enhance the construct and internal validity of our conceptual framework, whereas we sought to strengthen its reliability and external validity via data triangulation among different sources (Eisenhardt, 1989). However, it is critical to note that our work is based on only one focal firm. We selected our theoretical sample according to the main purpose of this paper, which is, as typical of case study research, to develop theory. Similar investigations of other companies and other industries are needed to provide further evidence for our conceptual framework. The next step is testing our emerging constructs (Eisenhardt and Graebner, 2007).

Scholars have already devoted considerable efforts into analyzing the reasons for the decline of Nokia. In his memoirs, former CEO Ollila (Ollila and Saukkomaa, 2013) emphasized the inability of the company to develop the software skills that it needed to cope with Apple. In addition, Vuori and Huy (2015) focused on the managers' emotions and the fear resulting from Ollila's aggressive behavior, and Laamanen et al. (2015) pointed to the company's pitfalls in strategic execution. Our research complements this previous work by offering a new perspective on Nokia's fortunes. We focus on a specific issue, i.e., the co-evolution of analogical reasoning and cognition in this company, that has remained largely neglected thus far.

We hope that despite its limitations, our research might inspire the future efforts of scholars and help expand our theoretical and empirical knowledge of the relationship among analogical reasoning, managerial beliefs, and long-term performance in a turbulent environment. 


\section{References}

Aspara, J., Lamberg, J.A., Laukia, A., Tikkanen, H., 2013. Corporate Business Model Transformation and Inter-Organizational Cognition: The Case of Nokia. Long Range Planning 46, 459-474.

Barr, P.S., 1998. Adapting to unfamiliar environmental events: A look at the evolution of interpretation and its role in strategic change. Organization Science 9 644-649.

Barr, P.S., Stimpert, J.L., Huff, A.S.,1992. Cognitive change, strategic action, and organizational renewal. Strategic Management Journal 13, 15-36.

Bettis, R., Gambardella, A., Helfat, C., Mitchell, W., 2015. Qualitative Empirical Research in Strategic Management, Strategic Management Journal 36, 637-639.

Brews, P.J. and Hunt, M., 1999. Learning to plan and planning to learn: resolving the planning school/learning school debate. Strategic Management Journal 20, 889-914.

Camerer, C., Lovallo, D. 1999. Overconfidence and excess entry: An experimental approach. American Economic Review 89, 306-318.

Charmaz, K. 2006. Constructing grounded theory: A practical guide through qualitative analysis. Sage Publications, Thousand Oaks, CA.

Christensen, C.M., 1997. The Innovator's Dilemma. Harvard University Press, Boston, MA.

Daft, R. L., Weick, W.E., 1984. Toward a model of organizations as interpretation systems. Academy of Management Review 9, 284-295.

de Geus, A., 1988. Planning as learning. Harvard Business Review 66, 70-74.

Dixit, A.K., Pindyck, R.S. 1994. Investment under Uncertainty. Princeton University Press, Princeton, NJ.

Doz, Y., Kosonen, M., 2008. Fast Strategy: How Strategic Agility Will Help You Stay Ahead of the Game. Wharton School Publishing, Philadelphia, PA.

Eggers, J.P., Kaplan, S., 2009. Cognition and renewal: Comparing CEO and organizational effects on incumbent adaptation to technical change. Organization Science 20, 461-477.

Eisenhardt, K.M., 1989. Building theories from case studies research. Academy of Management Review 14, 532-550.

Eisenhardt, K.M., Graebner, M.E., 2007. Theory building from cases: opportunities and challenges. Academy of Management Journal, 50, 25-32.

Eisenhardt, K.M., Graebner, M.E., Sonenshein S. 2016. Grand Challenges and Inductive Methods: Rigor without Rigor Mortis. Academy of Management Journal 59, 1113-1123.

Eisenhardt, K.M., Sull, D.N. 2001. Strategy as simple rules. Harvard Business Review 79, 106116.

Farmer, J.D., Lafond, F., 2016. How predictable is technological progress? Research Policy 45, 647-665.

Fiol, C.M., 1990. Explaining strategic alliance in the chemical industry. In A.S. Huff (Ed.), Mapping strategic thought. Wiley Chichester, New York, pp. 227-249.

Garud, R., Kumaraswamy, A. Karnøe, P., 2010. Path dependence or path creation? Journal of Management Studies 47, 760-74.

Garud, R., Rappa, M.A.,1994. A socio-cognitive model of technology evolution: the case of cochlear implants. Organization Science 5, 344-62.

Gary, S.G. Wood, R.E., Pillinger, T. 2012. Enhancing mental models, analogical transfer, and performance in strategic decision making. Strategic Management Journal 33, 1229-1246. 
Gavetti, G., Levinthal, D.A., Rivkin, J.W. 2005. Strategy making in novel and complex worlds: The power of analogy. Strategic Management Journal 26, 691-712.

Gavetti, G., Menon, A., 2016. Evolution cum agency: Toward a model of strategic foresight. Strategy Science 1, 207-233.

Gentner, D. 1983. Structure-mapping: A theoretical framework for analogy. Cognitive Science 7, 155-170.

Gilbert, C.G., 2006. Change in the presence of residual fit: can competing frames coexist'? Organization Science 17, 150-167.

Gilboa, I., Schmeidler, D., 2001. A Theory of Case-Based Decisions. Cambridge University Press, Cambridge, UK.

Glaser, B.G., Strauss, A.L. 1967. The discovery of grounded theory. Aldine, Chicago, IL.

Goll, I., Rasheed, A.M.A., 1997. Rational decision-making and firm performance: the moderating role of environment. Strategic Management Journal 18, 583-591.

Grant, R.M., 2003. Strategic planning in a turbulent environment: evidence from the oil majors. Strategic Management Journal 24, 491-517.

Hambrick, D.C., 1982. Environmental scanning and organizational strategy'. Strategic Management Journal 3, 159-174.

Hekkert, M.P., Suurs, R.A.A., Negro, S.O., Smits, R.E.H.M., Kuhlmann, S., 2007. Functions of innovation systems: a new approach for analyzing technological change. Technological Forecasting and Social Change 74, 413-432.

Hoisl, K., Stelzer, T., Biala, S., 2015. Forecasting technological discontinuities in the ICT industry. Research Policy 44, 522-532.

Jackson, S.E., Dutton, J.E. 1988. Discerning threats and opportunities. Administrative Science Quarterly 33, 370-387.

Kahneman, D., Lovallo, D., 1993. Timid choices and bold forecasts: A cognitive perspective on risk taking. Management Science 39, 17-31.

Kaplan, S., 2008a. Cognition, capabilities, and incentives: Assessing firm response to the fiberoptic revolution. Academy of Management Journal 51, 672-695.

Kaplan, S., 2008b. Framing contests: strategy making under uncertainty. Organization Science, $19,729-752$

Kaplan, S., 2011. Research in cognition and strategy: Reflections on two decades of progress and a look to the future. Journal of Management Studies 48, 665-695.

Kaplan, S., Murray, F., Henderson, R.M., 2003. Discontinuities and senior management: Assessing the role of recognition in pharmaceutical firm response to biotechnology. Industrial and Corporate Change 12, 203-233.

Kaplan, S., Tripsas, M., 2008. Thinking about technology: applying a cognitive lens to technical change. Research Policy 37, 790-805.

Kappel, T.A., 2001. Perspectives on roadmaps: how organizations talk about the future. Journal of Product Innovation Management 18, 39-50.

Kiesler, S., Sproull, L., 1982. Managerial response to changing environments: perspectives on problem sensing from social cognition. Administrative Science Quarterly 27, 548-570.

Klayman, J., Schoemaker, P.J.H., 1993. Thinking about the future: A cognitive perspective. Journal of Forecasting 12, 161-186. 
Klayman, J., Soll, J., Gonzalez-Vallejo, J., Barlas, S. 1999. Overconfidence: It depends on how, what, and whom you ask. Organizational Behavior and Human Decision Processes 79, 216-247.

Koryak, O., Lockett, A., Hayton, J., Nicolaou, N., Mole, K., 2018. Disentangling the antecedents of ambidexterity: exploration and exploitation. Research Policy 47, 413-427.

Krychowski, C., Quelin, B.V., 2010. Real options and strategic investment decisions: Can they be of use o scholars? Academy of Management Perspectives 4, 65-78.

Kumar, N., Stern, L.W., Anderson, J.C., 1993. Conducting interorganizational research using key informants. Academy of Management Journal 36, 1633-1651.

Laamanen, T., Lamberg, J.H., Vaara, E., 2016. Explanations of success and failure in management learning: What can we learn from Nokia's rise and fall? Academy of Management Learning \& Education 15, 12 -25.

Laamanen, T., Wallin, J., 2009. Cognitive dynamics and capability development paths'. Journal of management Studies 46, 950-981.

Lieberman, M.B., Montgomery, D.B., 1988. First-mover advantages. Strategic Management Journal 9, 41-58.

Locke, K., 2001. Grounded Theory in Management Research. Sage, London.

Loewenstein, J., Thompson, L., Gentner D. 2003., Analogical learning in negotiation teams: Comparing cases promotes learning and transfer. Academy of Management Learning 2,119-127.

May, R., Stewart, W., Sweo, R., 2000. Environmental scanning in a transitional economy. Academy of Management Journal 43, 403-427.

McGrath, R. G., Ferrier, W.J., Mendelow, A. L., 2004. Real options as engines of choice and heterogeneity. Academy of Management Review 29, 86-101.

Miles, M.B., Huberman, A.M., 1994. Qualitative data analysis: An expanded sourcebook (2nd ed.). Sage, Thousands Oaks, CA.

Mintzberg, H., 1990. The design school: reconsidering the basic premises of strategic management. Strategic Management Journal 11, 171-195.

Nadkarni, S., Barr, P.S., 2008. Environmental context, managerial cognition, and strategic action: An integrated view. Strategic Management Journal 29, 1395-1427.

Nightingale, P., 1998. A cognitive model of innovation. Research Policy 27, 689-709.

Nightingale, P., 2004. Technological capabilities, invisible infrastructure and the un-social construction of predictability: the overlooked fixed costs of useful research. Research Policy 33, 1259-1284.

Ocasio, W., 1997. Towards an attention-based view of the firm. Strategic Management Journal 18, 187-206.

Ollila, J., Saukkoma, H., 2013. Mahdoton menestys. Porvoo, Otava.

Phaal, R., Farrukh, C.J.P., Probert, D., 2004. Technology roadmapping-A planing framework for evolution and revolution. Technological Forecasting \& Social Change 71, 5-26.

Phadnis, S., Caplice, C., Sheffi, Y., Singh, M., 2015. Effect of scenario planning on field experts' judgement of long-range investment decisions. Strategic Management Journal 36, 14011411

Porac, J. F., Thomas, H., Wilson, F., Paton, D., Kanfer, A., 1995. Rivalry and the industry model of Scottish knitwear producers. Administrative Science Quarterly 40, 203-227.

Porter, A.L., Cunningham, S.W., Banks, J., Roper, A.T., Mason, T.W., Rossini, F.A., 2011. 
forecasting and Management of Technology. John Wiley \& Sons, Hoboken, NJ.

Prahalad, C.K., Bettis, R.A., 1986. The dominant logic: a new linkage between diversity and performance. Strategic Management Journal 76, 485-501.

Rerup, C., 2009. Attentional triangulation: Learning from unexpected rare crises. Organization Science 20, 876-893.

Schoemaker, P.J.H., 1993. Multiple scenario development: its conceptual and behavioral foundation. Strategic Management Journal 14, 193-213.

Schwartz, P., 1991. The Art of the Long View: Planning for the Future in an Uncertain World. Doubleday Currency, New York.

Simon, H.A., 1955. A behavioral model of rational choice. Quarterly Journal of Economics 69, 99-118.

Simon, M., Houghton, S.M., 2003. The relationship between overconfidence and the introduction of risky products: Evidence from a field study. Academy of Management Journal 46, 139-149.

Smit, J.T.J., Trigeorgis, L., 2004. Strategic investment: Real options and games. Princeton University Press, Princeton, NJ.

Steinbock, D., 2001. The Nokia Revolution. Amacon, New York.

Strauss, A., Corbin. J., 1990. Basics of qualitative research: Grounded theory procedures and techniques. Sage Publications, Newbury Park, CA.

Szulanski, G., Doz, Y., Ovetzky, Y., 2004. Incumbents' framing: three established companies respond to the internet. Advances in Strategic Management: Business Strategy Over the Industry Life Cycle 21, 77-106.

Teece, D.J., 2007. Explicating dynamic capabilities: the nature and microfoundations of (sustainable) enterprise performance. Strategic Management Journal 28, 1319-1350.

Thomas, J.B., Clark, S.M., Gioia, D.A., 1993. Strategic sensemaking and organizational performance: Linkages among scanning, interpretation, action, and outcomes. Academy of Management Journal 36, 239270.

Thrane, S., Blaabjerg, S., Molle, R.H., 2010. Innovative path dependence: making sense of product and service innovation in path dependent innovation processes. Research Policy 39, 932-944.

Tong, T.W., Reuer, J.J., 2007. Real options in strategic management. In J.J. Reuer and T.W. Tong (Eds.), Advances in Strategic Management. Emerald Group Publishing Ltd., Greenwich 24, 3-28.

Tripsas, M., Gavetti, G., 2000. Capabilities, cognition, and inertia: evidence from digital imaging. Strategic Management Journal 21, 1147-1162.

Vuori, T.O., Huy, Q.N., 2015. Distributed attention and shared emotions in the innovation process: How Nokia lost the smartphone battle. Administrative Science Quarterly 58, 1154-1178.

Walsh, J.P., 1995. Managerial and organizational cognition: Notes from a trip down memory lane. Organization Science 6, 280-321.

Yin, R.K., 2003. Case study research: Design and methods (3rd ed.). Sage, Newbury Park, CA. 


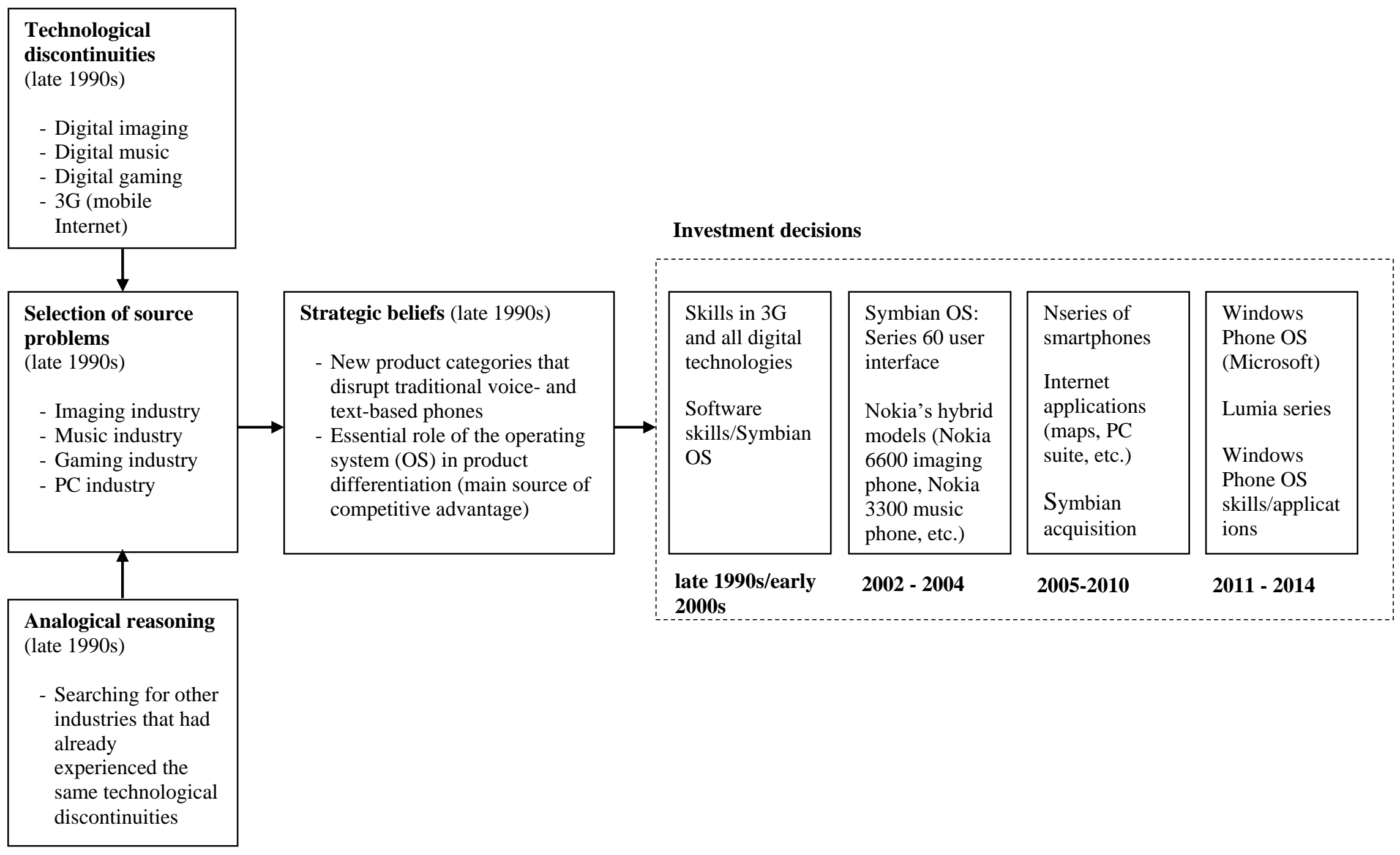

Fig. 1. Analogical reasoning, beliefs, and investment decisions at Nokia (1998 - 2014) 


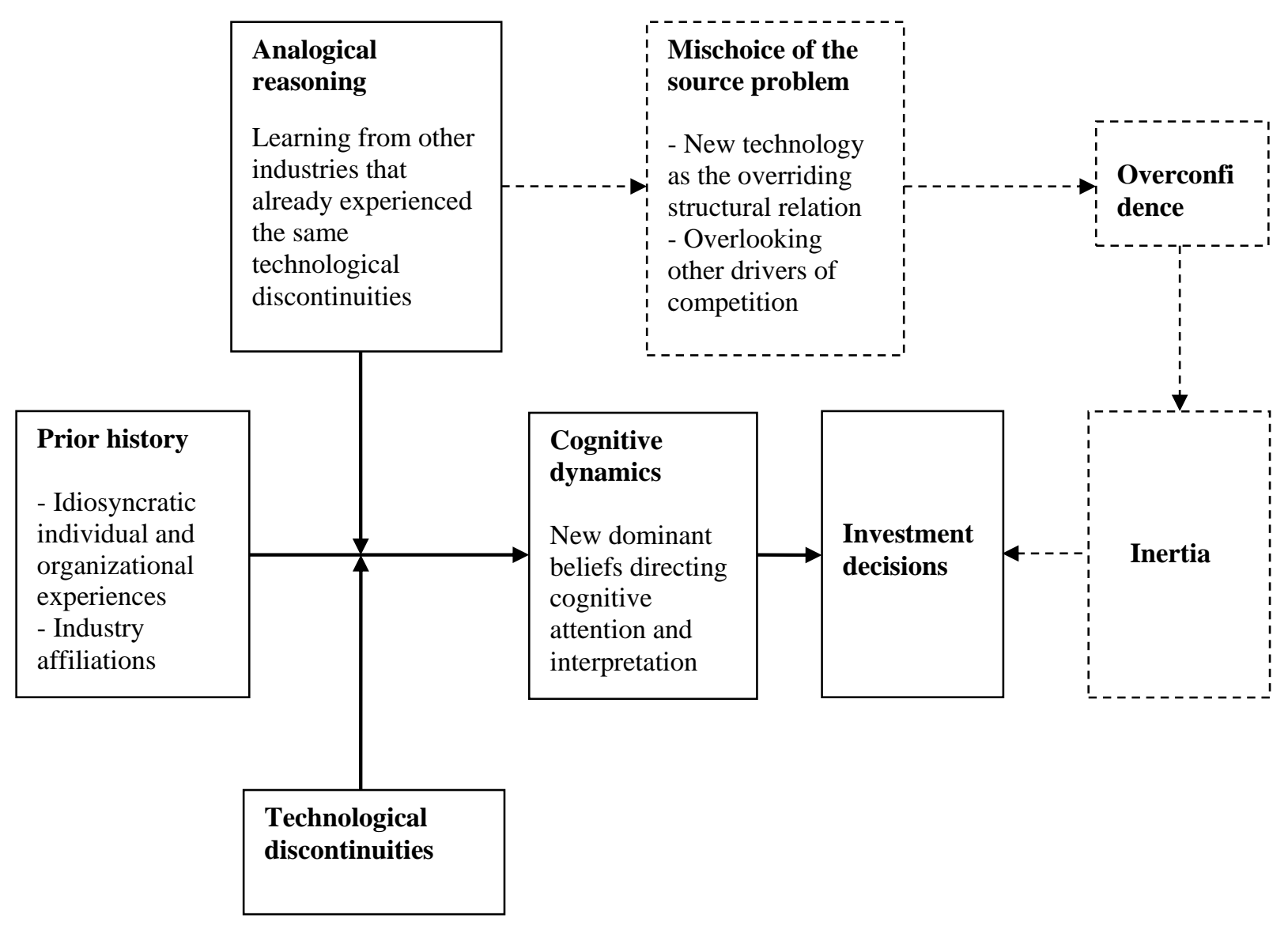

Fig. 2. Relationship among analogical reasoning, cognition, and technology competition outcomes: Lessons from Nokia 